\title{
BMJ Open Electrocardiography for the detection of left ventricular hypertrophy in an elderly population with long-standing hypertension in primary care: a secondary analysis of the CHELLO cohort study
}

\author{
Josephine Madeleine Louise de Hartog-Keyzer (10 , , Saloua El Messaoudi, ${ }^{1}$ \\ Ralf Harskamp, ${ }^{2}$ Priya Vart, ${ }^{1,3}$ Lianne Ringoir, ${ }^{4}$ Victor Pop, ${ }^{5}$ Robin Nijveldt ${ }^{1}$
}

To cite: de Hartog-Keyzer JML, El Messaoudi S, Harskamp R, et al. Electrocardiography for the detection of left ventricular hypertrophy in an elderly population with long-standing hypertension in primary care: a secondary analysis of the CHELLO cohort study. BMJ Open 2020;10:e038824. doi:10.1136/ bmjopen-2020-038824

- Prepublication history for this paper is available online. To view these files, please visit the journal online (http://dx.doi org/10.1136/bmjopen-2020038824).

Received 25 March 2020 Revised 08 July 2020 Accepted 15 July 2020

D) Check for updates

(c) Author(s) (or their employer(s)) 2020. Re-use permitted under CC BY-NC. No commercial re-use. See rights and permissions. Published by BMJ.

For numbered affiliations see end of article.

\section{Correspondence to} Josephine Madeleine Louise de Hartog-Keyzer;

josephine_keyzer@hotmail.com

\section{ABSTRACT}

Objectives To investigate: (1) the prevalence of left ventricular hypertrophy $(\mathrm{LVH})$ in elderly primary care patients with long-standing asymptomatic hypertension, and (2) the diagnostic value of ECG as a screening tool in the detection of LVH compared with echocardiography in this specific patient population.

Design and settings A cross-sectional study in five general practices in the south-east of the Netherlands. Participants Patients with primary care-managed hypertension, aged between 60 and 85 years, without known heart failure.

Primary and secondary outcome measures Between June 2010 and January 2013, the patients underwent structured interviews, blood pressure assessment, laboratory testing, ECGs and echocardiograms. The primary outcome was to investigate the ability of ECG to detect LVH, compared with echocardiography as a reference test (gold standard).

Results Four hundred and twenty-two patients (44\% male; ages $70 \pm 7$ years) who underwent ECG and echocardiographic assessment to determine LVH were included. The median duration of hypertension was 10 (4-15) years. The overall prevalence of LVH was $44 \%$, which increased with age $(p<0.001)$; up to $60 \%$ of patients were $\geq 75$ years. ECG intimated LVH in 47 patients (11\%) but in only 26 of those (55\%) was LVH confirmed by echocardiography. The sensitivity of ECG for detecting LVH was poor (14\%).

Conclusions Asymptomatic primary care patients with long-standing hypertension have a high prevalence of previously undetected LVH, which increases with age. ECG is inadequate for detecting LVH in these patients. Early detection of LVH could potentially create more awareness for the optimal regulation of hypertension and compliance to therapy. Therefore, echocardiography should be considered a screening device for the detection of LVH in this population.

\section{INTRODUCTION}

Worldwide, hypertension is a common and increasingly frequent condition in the adult population. ${ }^{1}$ A prevalence of up to $62 \%$ has been reported in the adult population of $60-70$ years of age. ${ }^{2}$ It is the most important
Strengths and limitations of this study

- In a primary care population of asymptomatic elderly individuals with long-standing hypertension: we report prevalence of left ventricular hypertrophy (LVH) by echocardiogram and the ability of ECG to detect this condition that has been associated with adverse outcomes.

- No long-term follow-up data on the occurrence of cardiac events are currently available, so adverse outcomes of LVH detected by ECG or echocardiography for future cardiovascular events remain unclear in this study,

- The design of the study has its limitations: it consists of a cross-sectional cohort without a control group for comparison.

(modifiable) risk factor for developing cardiovascular disease (CVD), including myocardial infarction (MI), stroke, atrial fibrillation and heart failure. ${ }^{3}$ Clinical findings related to hypertensive heart disease include left ventricular hypertrophy $(\mathrm{LVH})$, secondary left ventricular (LV) diastolic dysfunction and left atrial dilation. LV diastolic dysfunction is a well-known cause of heart failure, leading to high morbidity and mortality. ${ }^{4}$ The detection of LVH is important because these patients' risk of cardiovascular (CV) morbidity and mortality is twofold to fourfold increased, compared with patients with normal LV mass. $^{5}$

Most patients with hypertension are diagnosed in primary care. The first choice of treatment is lifestyle and dietary interventions, followed by drug therapy. Achieving adequate blood pressure control is pivotal in reducing the risks of hypertension-mediated organ damage. In the Netherlands, general practitioners treat patients according to the 
latest nationwide guidelines for $\mathrm{CV}$ risk management. ${ }^{6}$ However, these guidelines are conservative in their recommendations for additional testing after laboratory and blood pressure assessments. Standard ECG and echocardiography are not recommended in these guidelines to screen for, among other things, LVH. In particular, in long-standing hypertension with known high morbidity and mortality, LVH should be recognised using the most reliable method available, ${ }^{7}$ in order to intensify the regulation of blood pressure so that LVH can be modified in time. ${ }^{89}$ This will hopefully increase patient awareness and adherence to therapy.

Moreover, the value of ECG screening in primary care patients with hypertension has not yet been fully explained. The increase in myocardial wall thickness is the most apparent finding with regard to end-organ damage due to uncontrolled hypertension and elevated pressure load. ${ }^{10}$ This may first be noted by ECG, using specific criteria, ${ }^{11}$ however, the sensitivity to diagnose LVH in a general population is low, in comparison to echocardiography as the reference gold standard. ${ }^{12}{ }^{13}$ In primary care, though, ECG is still the preferred tool in patients with hypertension, since it is easy to obtain, fast and inexpensive. With the increasing accessibility of ultrasound machines to primary care physicians, it is important to decide whether ECG remains a viable tool as first choice for detecting $\mathrm{LVH}$, or perhaps in selected patients only. It is conceivable that in patients with longer duration of hypertension, having a higher incidence and higher rates of severe LVH due to chronic pressure overload, ${ }^{14}$ ECG may still have a diagnostic role.

The aim of the current study was to investigate: (1) the prevalence of LVH in elderly primary care patients with long-standing asymptomatic hypertension, and (2) the diagnostic value of electrocardiography as a screening tool in the detection of LVH compared with echocardiography in this specific patient population.

\section{METHODS}

\section{Study design and patient population}

This study was performed using data from the CHELLO (Chronic Heart Failure Prevention Program) study. The details of this study have been presented earlier. ${ }^{15-17}$ In summary, between June 2010 and January 2013, a total of 913 primary care patients aged between 60 and 85 years with an International Classification of Primary Care for hypertension (K86/K87) were invited from five general practices affiliated with the primary care organisation Praktijkondersteuning Zuidoost Brabant to participate in the CHELLO study.

Inclusion criteria were: elderly primary care patients (60-85 years) with asymptomatic hypertension. Patients with a history of CVD (eg, MI) were included if they were no longer treated by a cardiologist. Exclusion criteria: patients with heart failure were excluded based on nature of the primary study (Chronic Heart Failure Prevention Program).
Other exclusion criteria included: severe psychiatric illness other than mood or anxiety disorders; serious cognitive impairment; terminal cancer; insufficient knowledge of the Dutch language; or illiteracy. This resulted in 595 eligible patients who gave written informed consent for participation.

\section{Patient and public involvement}

No patient involved.

\section{Study procedure and data collection}

Eligible patients received both verbal and written information on the study. After obtaining written informed consent, an interview was scheduled at the primary care practice. During this first visit, a healthcare nurse conducted a structured interview and performed a physical examination. Blood pressure was measured automatically after approximately 20 and $40 \mathrm{~min}$, with the patient in a sitting position. The mean value of both blood pressure measurements was used for data analysis. In addition, demographic and clinical variables were obtained during the interview and after reviewing the patient's medical records. Following the first appointment, blood was drawn by venipuncture in order to measure brain natriuretic peptide (BNP), total cholesterol and lowdensity lipoprotein. BNP was measured since it is a known indicator of heart failure, which could be the result of long-term LVH. ${ }^{3}{ }^{18}$ A follow-up visit was planned at the primary care practice in order to perform an ECG and echocardiogram.

\section{Assessment of the ECG and echocardiogram}

The primary outcome was to investigate the ability of ECG to detect LVH, compared with echocardiography as a reference test (gold standard).

ECG and echocardiogram were carried out by a trained, experienced echocardiographer at the local primary care laboratory 'Diagnostiek voor U' in Eindhoven, the Netherlands.

A standard resting 12-lead ECG was recorded (paper speed $25 \mathrm{~mm} / \mathrm{s}, 10 \mathrm{~mm} / \mathrm{mV}$ ). We used the following eight well-known and often used criteria in order to evaluate the LVH features during ECG:

- The Sokolow-Lyon index: the sum of the $\mathrm{S}$ wave in V1 and the $\mathrm{R}$ wave in $\mathrm{V} 5$ of $\mathrm{V} 6>3.5 \mathrm{mV} .^{19}$

- The sum of the $\mathrm{S}$ wave in $\mathrm{V} 2$ and the $\mathrm{R}$ wave in $\mathrm{V} 5$ or $\mathrm{V} 6>4.5 \mathrm{mV}^{20}$

- The amplitude of the $\mathrm{R}$ wave in $\mathrm{V} 5$ or $\mathrm{V} 6>2.6 \mathrm{mV} .^{19}$

- A comparison of the amplitude of the $\mathrm{R}$ wave in V5 and V6; R V6>R V5. ${ }^{21}$

- The sum of the largest amplitude of the $\mathrm{R}$ wave and the largest amplitude of the $\mathrm{S}$ wave in precordial leads $>4.5 \mathrm{mV}^{22}$

- The Cornell voltage: the sum of the $\mathrm{R}$ wave in augmented vector left $(\mathrm{aVL})$ and the $\mathrm{S}$ wave in $\mathrm{V} 3>2.0$ $\mathrm{mV}$ for females and $>2.8 \mathrm{mV}$ for males. ${ }^{23}$

- The amplitude of the $\mathrm{R}$ wave in aVL $>1.1 \mathrm{mV}^{19}$ 
- The Gubner-Ungerleider voltage: the sum of the $\mathrm{R}$ wave in I and the S wave in the III lead $>2.5 \mathrm{mV}^{24}$

If one or more of these eight criteria were positive, ECG-LVH was diagnosed. An independent cardiologist who was blinded for outcomes of the echocardiogram gave a final review.

A transthoracic 2D echocardiographic examination was performed with an s5 transducer (Philips CX 50) in a standard position. All the echocardiograms were reviewed by a panel of cardiologists specialised in echocardiography, according to European recommendations and guidelines for evaluating chamber quantification, diastolic dysfunction and heart valve disease. ${ }^{25-27} \mathrm{LVH}$ was defined as any abnormal LV size measurement (septal or posterior wall thickness $>0.9 \mathrm{~cm}$ in females or $>1.0 \mathrm{~cm}$ in males) and calculated LV mass index adjusted for body surface area $>95 \mathrm{~g} / \mathrm{m}^{2}$ in females and $>115 \mathrm{~g} / \mathrm{m}^{2}$ in males. We used Cube formula for LV mass $=0.8 * 1.04 *[$ (IVS+LVID $\left.+\mathrm{PWT})^{3}-\mathrm{LVID}^{3}\right]+0.6$ g. $^{26}$

\section{Statistical analyses}

Statistical analyses were performed using the IBM Statistical Package for the Social Sciences V.25.0. Data are presented as mean $\pm \mathrm{SD}$ in the case of normally distributed data, median (interquartile interval) for non-normally distributed data and number (percentage) for nominal data. A p value $<0.05$ (two tailed) was considered to indicate statistical significance.

In order to examine the prevalence of LVH, we calculated the proportion of patients with echocardiographydiagnosed LVH. In addition, we computed the 95\% CI for this estimate. In order to examine the diagnostic yield of ECG, we calculated sensitivity, specificity, positive predictive value (PPV) and negative predictive value (NPV) with a 95\% CI. McNemar's test was used to compare LVH detection rates between ECG and echocardiography in $2 \times 2$ contingency tables. In addition, the kappa measure of agreement value was calculated.

To assess a potential effect of age on our result, we divided our population $(n=422)$ into four groups: group $1(n=116)$ less than 65 years old; group $2(n=102) 65-69$ years old; group $3(\mathrm{n}=102) 70-74$ years old; group 4 $(\mathrm{n}=102) 75$ years and older.

In order to assess the discriminative ability of ECG, we compared the demographic, lifestyle and clinical characteristics of patients without LVH and patients with LVH. Characteristics were compared using an independent samples t-test for normally distributed continuous data, the Mann-Whitney U test for non-normally distributed continuous data and the $\chi^{2}$ test for categorical data. In the same way, the discriminative ability of echocardiograms was assessed.

Finally, in order to investigate whether the ECG, together with other demographic and clinical variables, can be used as a proxy for the echocardiogram when diagnosing $\mathrm{LVH}$, we performed single and subsequent multiple logistic regression analyses with LVH (normal \pm abnormal) using the echocardiogram as the dependent variable. The multivariable logistic regression model was constructed using backward selection $\left(\mathrm{p}_{\text {out }}>0.1\right)$, including variables that were significantly associated with LVH on the echocardiogram in univariable analyses.

\section{RESULTS}

\section{Study population}

A total of 427 patients from the CHELLO study cohort (595), with both an ECG and an echocardiogram, were included. Five patients were excluded due to the poor image quality of the echocardiogram, resulting in a total of 422 eligible patients. ${ }^{15-17}$

\section{Baseline characteristics}

Table 1 presents the baseline characteristics of the study participants. The mean age of these patients was $69.7 \pm 6.5$ years, with the minority being male $(44 \%, \mathrm{n}=186)$. The median years of hypertension amounted to 10 [4-15] years. Mean systolic blood pressure (SBP) was 149.2 \pm 20.2 $\mathrm{mm} \mathrm{Hg}$, and mean diastolic blood pressure was $81.8 \pm 10.8$ $\mathrm{mm} \mathrm{Hg}$. In all the patients, $67 \%$ had an SBP $>140 \mathrm{~mm}$ $\mathrm{Hg}(\mathrm{n}=281)$, and as much as $44 \%$ an SBP $>150 \mathrm{~mm} \mathrm{Hg}$ $(n=185)$. Therefore, in this population, $42 \%(n=175)$ had an SBP that was on target according to the Dutch guidelines for $\mathrm{CV}$ risk management. On-target SBP was defined as $<140 \mathrm{~mm} \mathrm{Hg}$ for those aged less than 70 years and $<150$ $\mathrm{mm} \mathrm{Hg}$ for those aged 70 years or older. ${ }^{6}$

\section{Prevalence and diagnostic yield of LVH using ECG compared with echocardiography}

The overall prevalence of LVH using echocardiogram was $44 \%(n=184)$, while that of LVH using ECG was $11 \%(n=47)$.

Of the 422 patients, 47 (11\%) had LVH using ECG and, of these 47 patients, 26 (55\%) had LVH confirmed using echocardiography. In other words, in almost half of those patients with LVH detected using ECG, this was not confirmed by echocardiography.

ECG had a sensitivity of $14 \%$ (95\% CI 9.44\% to $20.02 \%$ ), a specificity of $91 \%$ (95\% CI $86.83 \%$ to $94.46 \%$ ), a PPV of $56 \%(95 \%$ CI $41.86 \%$ to $68.04 \%$ ) and an NPV of $58 \%$ (95\% CI $56.13 \%$ to $59.58 \%$ ) for the detection of LVH using echocardiography.

Detection of LVH using ECG was not associated with LVH using echocardiography based on McNemar's test $(p<0.001)$. There was poor agreement between ECG and echocardiogram used for the detection of LVH (kappa $0.058, \mathrm{p}=0.086$ ). A typical example of LVH mismatch is demonstrated in figure 1 .

\section{Prevalence of LVH in different age categories using ECG and echocardiogram}

The prevalence of LVH using ECG increased with increasing age, however not significantly $\left(\chi^{2}(3)=5.06, p=0.17\right)$. The prevalence of LVH using echocardiography increased significantly with increasing age $\left(\chi^{2}(3)=18.58, \mathrm{p}<0.001\right)$. Figure 2 shows the distribution of LVH using ECG and echocardiography in the four different age categories. 


\begin{tabular}{|c|c|}
\hline Characteristic & $\begin{array}{l}\text { Total patients } \\
\mathrm{n}=422\end{array}$ \\
\hline \multicolumn{2}{|l|}{ Demographics } \\
\hline Age (mean, SD) & $69.7 \pm 6.5$ \\
\hline Male $(n, \%)$ & $186(44.1)$ \\
\hline Low education (n, \%) & $53(12.6)$ \\
\hline Having a partner $(\mathrm{n}, \%)$ & $327(77.5)$ \\
\hline \multicolumn{2}{|l|}{ Lifestyle } \\
\hline Current smoker (n, \%) & $54(12.8)$ \\
\hline Regular alcohol use $(\mathrm{n}, \%)^{*}$ & $135(32.0)$ \\
\hline Recommended physical exercise $(\mathrm{n}, \%) \dagger$ & $68(16.1)$ \\
\hline \multicolumn{2}{|l|}{ Clinical characteristics and risk factors } \\
\hline Previous MI (n, \%) & $19(4.5)$ \\
\hline Peripheral artery disease $(n, \%)$ & $18(4.3)$ \\
\hline Previous TIA/stroke (n, \%) & $36(8.5)$ \\
\hline Diabetes (n, \%) & $39(9.2)$ \\
\hline BMI (mean, SD) $\ddagger$ & $28 \pm 4.6$ \\
\hline BNP (median, IQR)§ & $10(6-18)$ \\
\hline Total cholesterol (mean, SD)ף & $5.1 \pm 1.0$ \\
\hline LDL (mean, SD) & $3.1 \pm 0.9$ \\
\hline SBP (mean, SD) & $149 \pm 20.2$ \\
\hline $\mathrm{SBP}>140(n, \%)$ & $281(66.6)$ \\
\hline SBP >150 (n, \%) & $185(43.8)$ \\
\hline DBP (mean, SD) & $81.8 \pm 10.8$ \\
\hline DBP >90 (n, \%) & $86(20.4)$ \\
\hline Blood pressure on target $(\mathrm{n}, \%)^{* *}$ & $175(41.5)$ \\
\hline Years of hypertension (median, IQR)ף & $10(4-15)$ \\
\hline
\end{tabular}

Values for categorical variables are given as number (percentage); values for continuous variables are given as mean \pm SD or median (IQR).

*Defined as $\geq 2$ glasses of alcohol per day on average.

†Defined as $\geq 30$ min exercise per day, at least five 5 days/week. $\ddagger \mathrm{n}=418$.

$\S \mathrm{n}=400$.

१n=407 due to missing data.

**On-target systolic blood pressure defined as $<140 \mathrm{~mm} \mathrm{Hg}$ for persons aged less than 70 years and $<150 \mathrm{~mm} \mathrm{Hg}$ for persons aged 70 years or more.

BMI, body mass index; BNP, brain natriuretic peptide; DBP, diastolic blood pressure; LDL, low-density lipoprotein; MI, myocardial infarction; SBP, systolic blood pressure; TIA, transient ischaemic attack.

The prevalence of LVH confirmed by echocardiography increased from $33 \%$ in the youngest age group $(<65$ years $)$ to $60 \%$ in the oldest age group ( $>74$ years), while the prevalence of LVH using ECG only increased from $11 \%$ in the youngest age group to $18 \%$ in the oldest age group.

\section{Study characteristics with regard to LVH status using ECG and} echocardiogram

Table 2 presents patient characteristics with regard to LVH using ECG and echocardiogram.
LVH was only significantly correlated with age using the echocardiogram; patients with LVH by echocardiography were older when compared with those without $\mathrm{LVH}(71 \pm 6.9$ vs $69 \pm 6.0, \mathrm{t}(420)=-4.29, \mathrm{p}<0.001)$. BNP was significantly higher in those with LVH on both ECG (17 $(9.9-31)$ vs $9.7(5.8-16.3), \mathrm{U}=5132, \mathrm{z}=-4.08, \mathrm{p}<0.001$, $\mathrm{r}=0.20)$ and echocardiography $(11(6.9-18)$ vs $9.8(5.3-$ 17), $\mathrm{U}=17$ 220, $\mathrm{z}=-2.11, \mathrm{p}=0.035, \mathrm{r}=0.11$ ) when compared with those without LVH. An elevated BNP was more strongly associated with LVH when using ECG than when using the echocardiogram.

Furthermore, only SBP was significantly higher in those with LVH using ECG compared with those without LVH $(155 \pm 23.1$ vs $149 \pm 19.7, \mathrm{t}(420)=-1.82, \mathrm{p}=0.041)$. Moreover, an SBP $>150 \mathrm{~mm} \mathrm{Hg}$ was significantly higher in those with LVH compared with those without LVH using ECG (60\% vs $42 \%, \chi^{2}(1)=5.32, p=0.021$ ).

With regard to the echocardiogram, patients with LVH were more likely to have had a previous MI compared with those without LVH ( $7 \%$ vs $3 \%, \chi^{2}(1)=4.98, p=0.026$ ). Moreover, the body mass index (BMI) was significantly higher in those with LVH using echocardiography compared with those without LVH $(29 \pm 4.3$ vs $28 \pm 4.7$, $\mathrm{t}(416)=-2.03, \mathrm{p}=0.043)$. Lastly, SBP was significantly higher in those with LVH on the echocardiogram, compared with those not suffering from LVH $(152 \pm 21.7$ vs $147 \pm 18.7$, $\mathrm{t}(420)=-2.69 \mathrm{p}=0.007)$.

\section{Predictors of LVH}

Table 3 presents the results from univariable and multivariable logistic regression analysis, with an abnormal echocardiogram LVH as the dependent variable. In univariable logistic regression analysis, greater age, previous MI, higher BMI, higher BNP, higher SBP and LVH on ECG were associated with echocardiogramdiagnosed LVH. After backward elimination, in multivariable logistic regression analysis, only greater age (OR $1.06,95 \%$ CI 1.03 to 1.10 ), previous MI (OR 2.86, 95\% CI 1.04 to 7.83 ) and higher BMI (OR 1.05, 95\% CI 1.01 to 1.10 ) were found to be predictors of echocardiogramdiagnosed LVH.

\section{DISCUSSION}

In this cross-sectional study of elderly asymptomatic primary care patients with long-standing hypertension, we found a prevalence of LVH of $44 \%$ using echocardiography. The prevalence of LVH detected with echocardiography increased significantly with age: up to $60 \%$ in patients older than 75 years. We also investigated the value of ECG in the detection of LVH compared with our findings with echocardiography. ECG had a poor predictive value to detect $\mathrm{LVH}$, with a low sensitivity of $14 \%$. In contrary to our echocardiography findings, we did not find an increase in prevalence of ECG-detected LVH with increasing age, prevalence stabilised at around 16\%-18\% in the highest age group. Early detection and subsequent treatment of $\mathrm{LVH}$ are important in an effort to reduce $\mathrm{CV}$ 


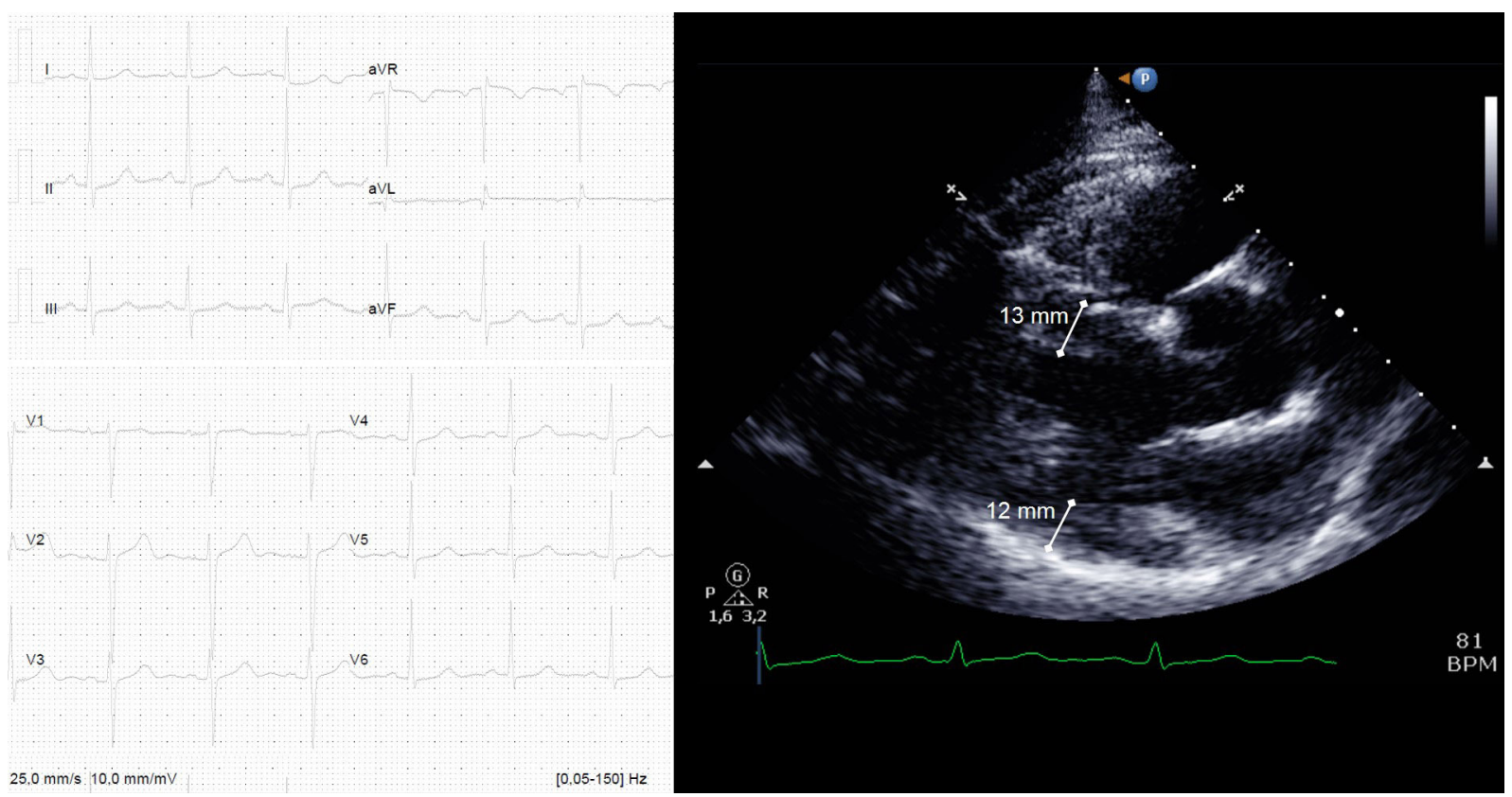

Figure 1 Normal ECG and abnormal echocardiogram of LVH in one patient. aVF, augmented vector foot; aVL, augmented vector left; aVR, augmented vector right; LVH, left ventricular hypertrophy.

morbidity and mortality, ${ }^{28}$ even in patients older than 65 years. ${ }^{29}$ Since most patients with hypertension are treated in primary care setting, there is a need for an easy, affordable and reliable screening tool to detect $\mathrm{LVH}$ in this population.

\section{Strengths and limitations}

In this study we evaluated the prevalence of LVH using echocardiography in a specific primary care cohort of asymptomatic elderly individuals with long-standing hypertension. Furthermore, we compared the ability of ECG to detect LVH with echocardiography as a reference test.

We conclude that there should be a standard role for echocardiography when screening for LVH in primary care patients with hypertension.

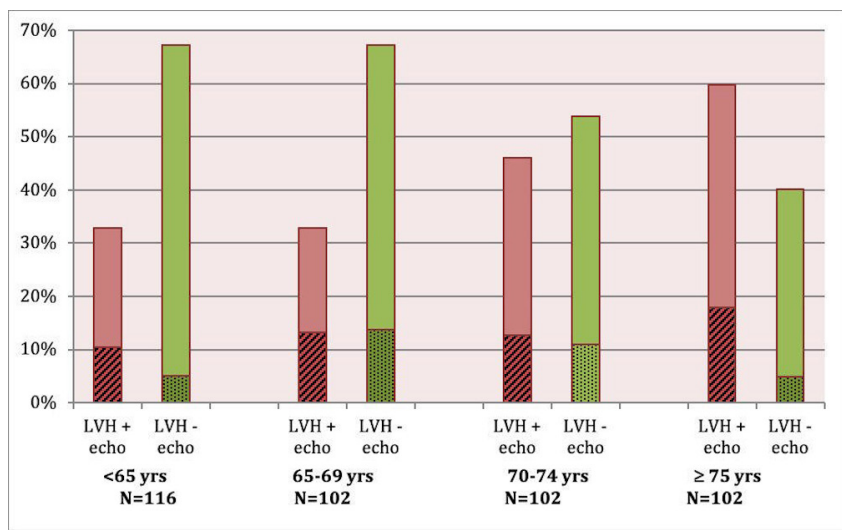

Figure 2 Prevalence of LVH using echocardiography and ECG (\%) in different age categories. Light red: LVH- ECG. Striped dark red: LVH+ ECG. Light green: LVH- ECG. Dotted dark green: LVH+ ECG. LVH, left ventricular hypertrophy.
One of the limitations of this study is that we used a cross-sectional design, without a control group for comparison. Furthermore, this study unfortunately lacks any long-term data on (cardiac) events, so adverse outcomes of LVH detected by ECG or echocardiography for the development of future CV events remain unclear in this population.

\section{Comparison with the existing literature}

The prevalence of echocardiographically confirmed LVH in the general population is estimated to be from $14 \%$ to $19 \%$, and increases with age ${ }^{3031}$ In our study, in a selected primary care patient population with long-standing hypertension, we noted a higher prevalence of LVH of $44 \%$. This corresponds with the prevalence of $\mathrm{LVH}$ reported in a recent review by Cuspidi et al, who noted a variation from $36 \%$ to $41 \%$ in patients with hypertension. ${ }^{32}$ Only limited data of prevalence of LVH in elderly primary care patients with hypertension are available. Doroudi et al reported a prevalence of LVH of $38 \%$ in patients in primary care, aged between 62 and 73, but this is a retrospective study. ${ }^{33}$ Chowdhury et al report a prevalence of LVH detected by the echocardiogram of $33 \%-70 \%$, depending on used definition. Although our reported prevalence of LVH detected with echocardiography $(44 \%)$ fits within this range, the study of Chowdhury et al did not comment on the value of ECG in detecting LVH in their population. ${ }^{34}$

The Framingham study pointed out that the use of ECG for detecting LVH in the general population was not reliable. ${ }^{12}$ They reported that ECG has a sensitivity of less than $20 \%$ for detecting LVH compared with echocardiography. When using cardiac MRI, Bacharova et al also reported the poor sensitivity (22\%) of ECG for detecting $\mathrm{LVH}$ in the general population. ${ }^{35}$ In a review of Pewsner 
Table 2 Characteristics according to LVH using ECG and echocardiogram

\begin{tabular}{|c|c|c|c|c|c|c|}
\hline \multirow[b]{2}{*}{ Characteristics } & \multicolumn{3}{|l|}{$\begin{array}{l}\text { ECG } \\
n=422\end{array}$} & \multicolumn{2}{|l|}{$\begin{array}{l}\mathrm{ECHO} \\
\mathrm{n}=422\end{array}$} & \multirow[b]{2}{*}{$P$ value } \\
\hline & $\begin{array}{l}\text { LVH+ } \\
\mathrm{n}=47\end{array}$ & $\begin{array}{l}\text { LVH- } \\
n=375\end{array}$ & $P$ value & $\begin{array}{l}\mathrm{LVH}+ \\
\mathrm{n}=184\end{array}$ & $\begin{array}{l}\text { LVH- } \\
n=238\end{array}$ & \\
\hline \multicolumn{7}{|l|}{ Demographics } \\
\hline Age (mean, SD) & $70.9 \pm 6.4$ & $69.5 \pm 6.5$ & 0.166 & $71.2 \pm 6.9$ & $68.5 \pm 6.0$ & $<0.001$ \\
\hline Male $(n, \%)$ & $23(48.9)$ & $163(43.5)$ & 0.476 & $83(45.1)$ & $103(43.3)$ & 0.707 \\
\hline Low education (n, \%) & $5(10.6)$ & $48(12.8)$ & 0.673 & $24(13.0)$ & $29(12.2)$ & 0.792 \\
\hline Having a partner (n, \%) & $37(78.7)$ & $290(77.3)$ & 0.830 & $141(76.6)$ & $186(78.2)$ & 0.711 \\
\hline \multicolumn{7}{|l|}{ Lifestyle } \\
\hline Current smoker (n, \%) & $4(8.5)$ & $50(13.3)$ & 0.351 & $19(10.3)$ & $35(14.7)$ & 0.182 \\
\hline Regular alcohol use $(n, \%)^{*}$ & $14(29.8)$ & $121(32.3)$ & 0.731 & $61(33.2)$ & $74(31.1)$ & 0.653 \\
\hline Recommended physical exercise $(\mathrm{n}, \%) \dagger$ & $8(17.0)$ & $60(16.0)$ & 0.858 & $28(15.2)$ & $40(16.8)$ & 0.660 \\
\hline \multicolumn{7}{|l|}{ Clinical characteristics and risk factors } \\
\hline Previous MI (n, \%) & $2(4.3)$ & $17(4.5)$ & 0.931 & $13(7.1)$ & $6(2.5)$ & 0.026 \\
\hline Peripheral artery disease $(n, \%)$ & $1(2.1)$ & $17(4.5)$ & 0.442 & $5(2.7)$ & $13(5.5)$ & 0.166 \\
\hline Previous TIA/stroke (n, \%) & $1(2.1)$ & $35(9.3)$ & 0.096 & $20(10.9)$ & $16(6.7)$ & 0.130 \\
\hline Diabetes (n, \%) & $4(8.5)$ & $35(9.3)$ & 0.854 & $19(10.3)$ & $20(8.4)$ & 0.499 \\
\hline BMI (mean, SD) $\ddagger$ & $27 \pm 4.0$ & $28 \pm 4.6$ & 0.178 & $29 \pm 4.3$ & $28 \pm 4.7$ & 0.043 \\
\hline BNP (median, IQR)§ & $17(9.9-31)$ & $9.7(5.8-16.3)$ & $<0.001$ & $11.0(6.9-18)$ & $9.8(5.3-17)$ & 0.035 \\
\hline Total cholesterol (mean, SD)ף & $5.2 \pm 1.1$ & $5.1 \pm 1.0$ & 0.522 & $5.1 \pm 1.1$ & $5.0 \pm 0.9$ & 0.286 \\
\hline LDL (mean, SD)ף & $3.2 \pm 0.9$ & $3.1 \pm 0.9$ & 0.746 & $3.2 \pm 0.9$ & $3.1 \pm 0.9$ & 0.361 \\
\hline SBP (mean, SD) & $155 \pm 23.1$ & $149 \pm 19.7$ & 0.041 & $152 \pm 21.7$ & $147 \pm 18.7$ & 0.007 \\
\hline SBP $>140(n, \%)$ & $33(70.2)$ & $248(66.1)$ & 0.576 & $128(69.6)$ & $153(64.3)$ & 0.254 \\
\hline $\mathrm{SBP}>150(n, \%)$ & $28(59.6)$ & $157(41.9)$ & 0.021 & $89(48.4)$ & $96(40.3)$ & 0.099 \\
\hline DBP (mean, SD) & $83.7 \pm 10.9$ & $81.6 \pm 10.7$ & 0.203 & $81 \pm 10.9$ & $82 \pm 10.6$ & 0.188 \\
\hline DBP >90 (n, \%) & $11(23.4)$ & $75(20.0)$ & 0.585 & $36(19.6)$ & $50(21.0)$ & 0.715 \\
\hline Blood pressure on target $(n, \%)^{\star \star}$ & 15 (31.9) & $160(42.7)$ & 0.158 & $71(38.6)$ & $104(43.7)$ & 0.291 \\
\hline Years of hypertension (median, IQR)ף & $10(4-15)$ & $10(4-16)$ & 0.629 & $10(4-20)$ & $8(4-15)$ & 0.188 \\
\hline
\end{tabular}

Values for categorical variables are given as number (percentage); values for continuous variables are given as mean \pm SD or median (IQR). $\chi^{2}$ test for nominal data, t-test for normally distributed continuous data, Mann-Whitney $\mathrm{U}$ test for non-normally distributed data. $\mathrm{P}$ values $<0.05$ are in bold.

${ }^{*}$ Defined as $\geq 2$ glasses of alcohol per day on average.

$\dagger$ Defined as $\geq 30$ min exercise per day, at least 5 days/week.

$\ddagger \mathrm{n}=418$.

$\S n=400$.

ๆn=407 due to missing data.

${ }^{* *}$ On-target systolic blood pressure defined as $<140 \mathrm{~mm} \mathrm{Hg}$ for persons aged less than 70 years and $<150 \mathrm{~mm} \mathrm{Hg}$ for persons aged 70 years or more.

BMI, body mass index; BNP, brain natriuretic peptide; DBP, diastolic blood pressure; ECHO, echocardiogram; LDL, low-density lipoprotein; $\mathrm{LVH}$, left ventricular hypertrophy; MI, myocardial infarction; SBP, systolic blood pressure; TIA, transient ischaemic attack.

et al, the studies in hypertensive primary care populations reported a median sensitivity ranged from $8.5 \%$ to $21 \%{ }^{36}$ Furthermore, in another large study Jain et al found a similar sensitivity range of $5.7 \%-26 \%$ for detecting LVH with ECG in a hypertensive population compared with MRI. ${ }^{37}$ We hypothesised that the reliability of ECG may be better in a selected group of patients with longstanding hypertension, which could be helpful in primary care practice. Unfortunately, our data show that ECG performed equally poor, even in this specific population.
Although our results have shown that ECG may not be recommended for the detection of $\mathrm{LVH}$, the prognostic value of ECG in elderly primary care patients with hypertension remains uncertain. It has been hypothesised that ECG may be of additional value for prognosis. ${ }^{78} 39$ Aro and Chugh suggested that LVH detected using ECG and LVH detected using echocardiography are two distinct entities that only partially overlap, and have different prognostic significance $^{40}$ (see figure 3 ). This hypothesis could explain the stronger association of elevated BNP 
Table 3 Univariable and multivariable association of LVH using echocardiogram with clinical parameters in patients with asymptomatic hypertension

\begin{tabular}{|c|c|c|c|c|}
\hline & \multicolumn{4}{|c|}{ LVH on echocardiogram } \\
\hline & \multicolumn{2}{|l|}{ Univariable } & \multicolumn{2}{|l|}{ Multivariable } \\
\hline & OR (95\% Cl) & $P$ value & OR (95\% Cl) & $P$ value \\
\hline \multicolumn{5}{|l|}{ Demographics } \\
\hline Higher age & 1.07 (1.04 to 1.10$)$ & $<0.001$ & 1.06 (1.03 to 1.10$)$ & 0.001 \\
\hline Male & 0.93 (0.63 to 1.37$)$ & 0.707 & & \\
\hline Low education & 1.08 (0.61 to 1.93$)$ & 0.792 & & \\
\hline Having a partner & 0.92 (0.58 to 1.45$)$ & 0.711 & & \\
\hline \multicolumn{5}{|l|}{ Lifestyle } \\
\hline Current smoker & 0.66 (0.37 to 1.21$)$ & 0.184 & & \\
\hline Regular alcohol use* & $1.10(0.73$ to 1.66$)$ & 0.653 & & \\
\hline Recommended physical exercise $†$ & 0.89 (0.53 to 1.50$)$ & 0.660 & & \\
\hline \multicolumn{5}{|l|}{ Clinical characteristics and risk factors } \\
\hline Previous MI & 2.94 (1.10 to 7.89$)$ & 0.032 & 2.86 (1.04 to 7.83$)$ & 0.041 \\
\hline Peripheral artery disease & 0.48 (0.17 to 1.38$)$ & 0.175 & & \\
\hline Previous TIA/stroke & 1.69 (0.85 to 3.37$)$ & 0.134 & & \\
\hline Diabetes & 1.26 (0.65 to 2.43$)$ & 0.500 & & \\
\hline Higher BMI‡ & 1.05 (1.00 to 1.09$)$ & 0.046 & 1.05 (1.01 to 1.10$)$ & 0.032 \\
\hline LnBNP§ & 1.35 (1.06 to 1.71$)$ & 0.014 & & \\
\hline Higher total cholesterolף & $1.12(0.91$ to 1.37$)$ & 0.278 & & \\
\hline Higher LDLף & 1.11 (0.89 to 1.38$)$ & 0.360 & & \\
\hline Higher SBP & 1.01 (1.00 to 1.02$)$ & 0.008 & & \\
\hline SBP $>140$ & 1.27 (0.84 to 1.92$)$ & 0.255 & & \\
\hline $\mathrm{SBP}>150$ & 1.39 (0.94 to 2.04$)$ & 0.099 & & \\
\hline Higher DBP & 0.99 (0.97 to 1.01$)$ & 0.188 & & \\
\hline $\mathrm{DBP}>90$ & 0.92 (0.57 to 1.48$)$ & 0.715 & & \\
\hline Blood pressure on target ${ }^{\star \star}$ & 1.24 (0.84 to 1.83$)$ & 0.291 & & \\
\hline More years of hypertensionๆ & 1.15 (0.94 to 1.41$)$ & 0.170 & & \\
\hline LVH on ECG & 1.70 (0.92 to 3.13$)$ & 0.088 & & \\
\hline
\end{tabular}

Data are presented as OR with corresponding $p$ value. Bold numbers indicate a $p$ value $<0.1$ at univariable analysis, and $p$ value $<0.05$ at multivariable analysis.

*Defined as $\geq 2$ glasses of alcohol per day on average.

†Defined as $\geq 30$ min exercise per day, at least 5 days/week.

$\ddagger n=418$.

$\S \mathrm{n}=400$.

१n=407 due to missing data.

${ }^{* \star}$ On-target systolic blood pressure defined as $<140 \mathrm{~mm} \mathrm{Hg}$ for persons aged less than 70 years and $<150 \mathrm{~mm} \mathrm{Hg}$ for persons aged 70 years or more.

BMI, body mass index; DBP, diastolic blood pressure; LDL, low-density lipoprotein; LnBNP, log-transformed brain natriuretic peptide; LVH, left ventricular hypertrophy; MI, myocardial infarction; SBP, systolic blood pressure; TIA, transient ischaemic attack.

with LVH using ECG as opposed to LVH using echocardiogram. The current study was unable to address this further.

\section{Implications for research and/or practice}

Our results provide additional proof that routinely acquired ECGs for detecting LVH in patients with hypertension have no significant diagnostic value, not even in a selected population with long-standing hypertension. On the other hand, ECG-derived LVH seems, at least partly, to be a different entity and a predictor of CV mortality, independent of LV mass index and LV morphology. Moreover, ECG-LVH increases the risk of CV mortality even in subjects without hypertension. ${ }^{41}{ }^{42}$ Routinely performing both ECG and echocardiography in patients with hypertension seems therefore indicated. Currently, both our national and European guidelines for $\mathrm{CV}$ risk management (in 


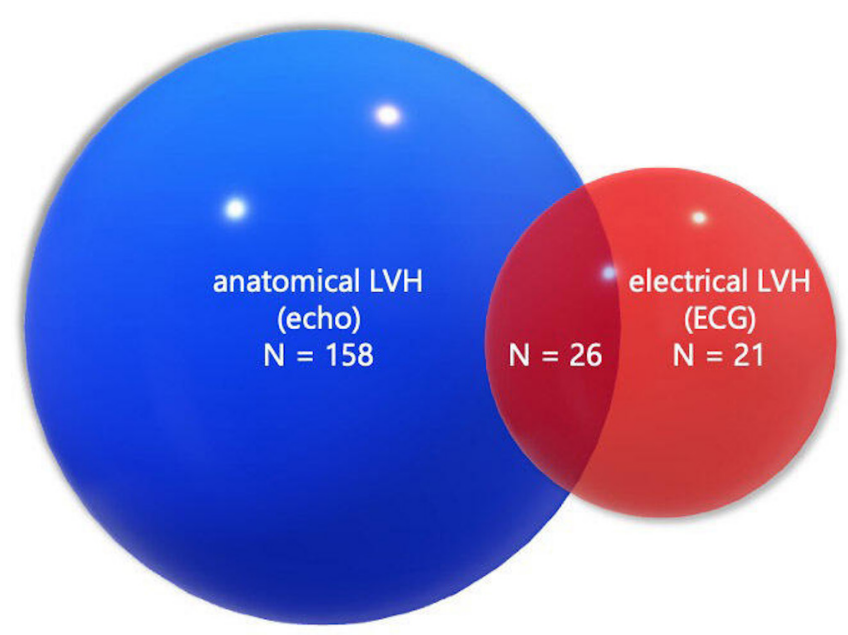

Figure 3 Anatomical versus electrical left ventricular hypertrophy (LVH) (adapted from Aro and Chugh [40] pointing out anatomical and electrical LVH, and their overlap, in our study).

primary care) do not recommend routinely performance of an ECG and/or echocardiogram.

Our findings point out that, when feasible, patients (particularly uncomplicated elderly patients with hypertension, who represent a large percentage of the population) should be referred for focused echocardiography for detection of LVH. ${ }^{43}$ Performing an ECG could be of additional prognostic value, independent of echocardiographic findings. ${ }^{73-42}$

Furthermore, our study showed that more than half the patients were not on target with their blood pressure, and it is possible that early recognition of $\mathrm{LVH}$ will increase patient awareness and adherence to therapy. Also, the early detection of $\mathrm{LVH}$ will identify patients who could benefit from intensified antihypertensive therapy, in order to prevent or delay the progression of CVD. ${ }^{282944-47}$

In conclusion, asymptomatic, elderly primary care patients with long-standing hypertension have a high prevalence of $\mathrm{LVH}$, which will increase with age. ECG is a suboptimal tool for detecting $\mathrm{LVH}$ and, for this reason, patients who are in need of close monitoring and stricter antihypertensive treatment may benefit from a cardiac evaluation with echocardiography. Further follow-up exploration is required to prove the prognostic value of ECG and echocardiography in this specific population of primary care patients with hypertension. Moreover, future research should concentrate on whether the early detection of $\mathrm{LVH}$ by echocardiography in the primary care setting leads to decreased morbidity and mortality in the increasing prevalence of hypertension.

\section{Author affiliations}

${ }^{1}$ Department of Cardiology, Radboudumc, Nijmegen, The Netherlands

2Department of General Practice, Amsterdam UMC, Amsterdam, The Netherlands

${ }^{3}$ Health Evidence, Radboudumc, Nijmegen, The Netherlands

${ }^{4}$ PoZoB, Veldhoven, The Netherlands

${ }^{5}$ Department of Medical Health Psychology, Tilburg University, Tilburg, The Netherlands
Acknowledgements The authors wish to thank the echocardiographist and technicians at the primary care laboratory 'Diagnostiek voor U'.

Contributors Conception of the work: JMLHK, SEM, VJP and RN. Data acquisition: JMLHK, LR. Data analysis: JMLHK, SEM, PV. Results interpretation: JMLHK, SEM, RH, PV, LR, VJP and RN. Drafting the work: JMLHK, SEM, VJP and RN. Comments on the manuscript draft: JMLHK, SEM, RH, PV, LR, VJP and RN. All the authors agreed on the final submitted version.

Funding The authors have not declared a specific grant for this research from any funding agency in the public, commercial or not-for-profit sectors.

Competing interests RN has received research grants from Philips and Biotronik. Patient consent for publication Not required.

Ethics approval This study complies with the Declaration of Helsinki and was approved by the Medical Ethics Board of the Saint Elisabeth Hospital, Tilburg, the Netherlands.

Provenance and peer review Not commissioned; externally peer reviewed. Data availability statement № data are available.

Open access This is an open access article distributed in accordance with the Creative Commons Attribution Non Commercial (CC BY-NC 4.0) license, which permits others to distribute, remix, adapt, build upon this work non-commercially, and license their derivative works on different terms, provided the original work is properly cited, appropriate credit is given, any changes made indicated, and the use is non-commercial. See: http://creativecommons.org/licenses/by-nc/4.0/.

\section{ORCID iD}

Josephine Madeleine Louise de Hartog-Keyzer http://orcid.org/ 0000-0002-8751-9627

\section{REFERENCES}

1 Egan BM, Zhao Y, Axon RN. Us trends in prevalence, awareness, treatment, and control of hypertension, 1988-2008. JAMA 2010;303:2043-50.

2 Blokstra A, Vissink P, Venmans L. Nederland de Maat Genomen 2012;27.

3 Williams B, Mancia G, Spiering W, et al. 2018 ESC/ESH guidelines for the management of arterial hypertension. Eur Heart $J$ 2018;39:3021-104

4 Bleumink GS, Knetsch AM, Sturkenboom MCJM, et al. Quantifying the heart failure epidemic: prevalence, incidence rate, lifetime risk and prognosis of heart failure the Rotterdam study. Eur Heart $J$ 2004;25:1614-9.

5 Katholi RE, Couri DM. Left ventricular hypertrophy: major risk factor in patients with hypertension: update and practical clinical applications. Int J Hypertens 2011;2011:495349.

6 Dis VI, Henstra Y, Den Hertog $\mathrm{H}$, et al. The NHG-Guideline cardiovascular risk management (second update). huisarts wetenschap 2019.

7 Cuspidi C, Facchetti R, Sala C, et al. Do combined electrocardiographic and echocardiographic markers of left ventricular hypertrophy improve cardiovascular risk estimation? J Clin Hypertens 2016;18:846-54.

8 Dahlöf B, Devereux RB, Kjeldsen SE, et al. Cardiovascular morbidity and mortality in the losartan intervention for endpoint reduction in hypertension study (life): a randomised trial against atenolol. Lancet 2002;359:995-1003.

9 Stewart $\mathrm{MH}$, Lavie CJ, Shah S, et al. Prognostic implications of left ventricular hypertrophy. Prog Cardiovasc Dis 2018;61:446-55.

10 Marwick TH, Gillebert TC, Aurigemma G, et al. Recommendations on the use of echocardiography in adult hypertension: a report from the European Association of Cardiovascular Imaging (EACVI) and the American Society of Echocardiography (ASE)†. Eur Heart $J$ Cardiovasc Imaging 2015;28:727-54.

11 Surawicz B, Childers R, Deal BJ, et al. AHA/ACCF/HRS recommendations for the standardization and interpretation of the electrocardiogram: Part III: intraventricular conduction disturbances: a scientific statement from the American heart association electrocardiography and arrhythmias Committee, Council on clinical cardiology; the American College of cardiology Foundation; and the heart rhythm Society: endorsed by the International Society for computerized Electrocardiology. Circulation 2009;119:e235-40.

12 Levy D, Garrison RJ, Savage DD, et al. Prognostic implications of echocardiographically determined left ventricular mass in the Framingham heart study. N Engl J Med 1990;322:1561-6. 
13 Haider AW, Larson MG, Benjamin EJ, et al. Increased left ventricular mass and hypertrophy are associated with increased risk for sudden death. J Am Coll Cardiol 1998;32:1454-9.

14 Levy D, Anderson KM, Savage DD, et al. Echocardiographically detected left ventricular hypertrophy: prevalence and risk factors. The Framingham heart study. Ann Intern Med 1988;108:7-13.

15 Ringoir L, Widdershoven JW, Pedersen SS, et al. Symptoms associated with an abnormal echocardiogram in elderly primary care hypertension patients. Neth Heart J 2014;22:234-9.

16 Ringoir L, Pedersen SS, Widdershoven JWMG, et al. Beta-blockers and depression in elderly hypertension patients in primary care. Fam Med 2014;46:447-53.

17 Ringoir L, Pedersen SS, Widdershoven JWMG, et al. Prevalence of psychological distress in elderly hypertension patients in primary care. Neth Heart J 2014;22:71-6.

18 Ponikowski P, Voors AA, Anker SD, et al. 2016 ESC Guidelines for the diagnosis and treatment of acute and chronic heart failure: The Task Force for the diagnosis and treatment of acute and chronic heart failure of the European Society of Cardiology (ESC)Developed with the special contribution of the Heart Failure Association (HFA) of the ESC. Eur Heart J 2016;37:2129-200.

19 Sokolow M, Lyon TP. The ventricular complex in left ventricular hypertrophy as obtained by unipolar precordial and limb leads. Am Heart J 1949;37:161-86.

20 Romhilt DW, Bove KE, Norris RJ, et al. A critical appraisal of the electrocardiographic criteria for the diagnosis of left ventricular hypertrophy. Circulation 1969;40:185-96.

21 Holt DH, Spodick DH. The Rv6:Rv5 voltage ratio in left ventricular hypertrophy. Am Heart J 1962;63:65-6.

22 McPhie J. Left ventricular hypertrophy: electrocardiographic diagnosis. Australas Ann Med 1958;7:317-27.

23 Casale PN, Devereux RB, Alonso DR, et al. Improved sex-specific criteria of left ventricular hypertrophy for clinical and computer interpretation of electrocardiograms: validation with autopsy findings. Circulation 1987;75:565-72.

24 Gubner R. Electrocardiographic criteria of left ventricular hypertrophy. Arch Intern Med 1943;72:196-209.

25 Galderisi M, Cosyns B, Edvardsen T, et al. Standardization of adult transthoracic echocardiography reporting in agreement with recent chamber quantification, diastolic function, and heart valve disease recommendations: an expert consensus document of the European association of cardiovascular imaging. Eur Heart $J$ Cardiovasc Imaging 2017;18:1301-10.

26 Lang RM, Badano LP, Mor-Avi V, et al. Recommendations for cardiac chamber quantification by echocardiography in adults: an update from the American Society of echocardiography and the European association of cardiovascular imaging. Eur Heart $J$ Cardiovasc Imaging 2015;16:233-71.

27 Nagueh SF, Smiseth OA, Appleton CP, et al. Recommendations for the evaluation of left ventricular diastolic function by echocardiography: an update from the American Society of echocardiography and the European association of cardiovascular imaging. Eur Heart J Cardiovasc Imaging 2016;17:1321-60.

28 Go AS, Mozaffarian D, Roger VL, et al. Heart disease and stroke statistics--2013 update: a report from the American Heart Association. Circulation 2013;127:e6-245.

29 Milan A, Caserta MA, Avenatti E, et al. Anti-hypertensive drugs and left ventricular hypertrophy: a clinical update. Intern Emerg Med 2010;5:469-79.
30 Schirmer H, Lunde P, Rasmussen K. Prevalence of left ventricular hypertrophy in a general population; the Troms $\varnothing$ study. Eur Heart J 1999;20:429-38.

31 Levy D, Savage DD, Garrison RJ, et al. Echocardiographic criteria for left ventricular hypertrophy: the Framingham heart study. Am J Cardiol 1987;59:956-60.

32 Cuspidi C, Sala C, Negri F, et al. Prevalence of leftventricular hypertrophy in hypertension: an updated review of echocardiographic studies. J Hum Hypertens 2012;26:343-9.

33 Doroudi S, DeLisi MD, DeBari VA. A review of echocardiograms in hypertensive patients greater than 60 years in a community based family medicine program. J Community Hosp Intern Med Perspect 2017;7:28-33.

34 Chowdhury EK, Jennings GLR, Dewar E, et al. Predictive performance of echocardiographic parameters for cardiovascular events among elderly treated hypertensive patients. Am J Hypertens 2016;29:821-31.

35 Bacharova L, Chen H, Estes EH, et al. Determinants of discrepancies in detection and comparison of the prognostic significance of left ventricular hypertrophy by electrocardiogram and cardiac magnetic resonance imaging. Am J Cardiol 2015;115:515-22.

36 Pewsner D, Jüni P, Egger M, et al. Accuracy of electrocardiography in diagnosis of left ventricular hypertrophy in arterial hypertension: systematic review. BMJ 2007;335:711.

37 Jain A, Tandri H, Dalal D, et al. Diagnostic and prognostic utility of electrocardiography for left ventricular hypertrophy defined by magnetic resonance imaging in relationship to ethnicity: the multiethnic study of atherosclerosis (MESA). Am Heart J 2010;159:652-8.

38 Patel N, O'Neal WT, Whalen SP, et al. Electrocardiographic left ventricular hypertrophy predicts atrial fibrillation independent of left ventricular mass. Ann Noninvasive Electrocardiol 2017;22:e12419-5.

39 Bacharova L, Schocken D, Estes EH, et al. The role of ECG in the diagnosis of left ventricular hypertrophy. Curr Cardiol Rev 2014;10:257-61.

40 Aro AL, Chugh SS. Clinical diagnosis of electrical versus anatomic left ventricular hypertrophy: prognostic and therapeutic implications. Circ Arrhythm Electrophysiol 2016;9:e003629.

41 Brown DW, Giles WH, Croft JB. Left ventricular hypertrophy as a predictor of coronary heart disease mortality and the effect of hypertension. Am Heart J 2000;140:848-56.

42 Tanaka K, Tanaka F, Onoda T, et al. Prognostic value of electrocardiographic left ventricular hypertrophy on cardiovascular risk in a non-hypertensive community-based population. Am J Hypertens 2018;31:895-901.

43 Bornemann P, Johnson J, Tiglao S, et al. Assessment of primary care physicians' use of a pocket ultrasound device to measure left ventricular mass in patients with hypertension. J Am Board Fam Med 2015;28:706-12.

44 Devereux RB, Wachtell K, Gerdts E, et al. Prognostic significance of left ventricular mass change during treatment of hypertension. JAMA 2004;292:2350-6.

45 Franz IW, Tönnesmann U, Müller JF. Time course of complete normalization of left ventricular hypertrophy during long-term antihypertensive therapy with angiotensin converting enzyme inhibitors. Am J Hypertens 1998;11:631-9.

46 Fagard $\mathrm{RH}$, Celis $\mathrm{H}$, Thijs L, et al. Regression of left ventricular mass by antihypertensive treatment: a meta-analysis of randomized comparative studies. Hypertension 2009;54:1084-91.

47 Klingbeil AU, Schneider M, Martus P, et al. A meta-analysis of the effects of treatment on left ventricular mass in essential hypertension. Am J Med 2003;115:41-6. 